Volume 3

Issue 4 -- Cardiovascular Aging

Article 20

$11-11-2016$

\title{
Identifying Disparities in Colorectal Cancer Screening Rates in Milwaukee-Based Academic and Nonacademic Clinics
}

Jasmine Wiley

Jonathan J. Blaza

Will Lehmann

Deborah Simpson

Jeffrey A. Stearns

Shelby L. Pischke

Tracy L. Greiten

Follow this and additional works at: https://aah.org/jpcrr

Part of the Community Health and Preventive Medicine Commons, Health Services Research

Commons, Oncology Commons, and the Public Health Education and Promotion Commons

\section{Recommended Citation}

Wiley J, Blaza JJ, Lehmann W, Simpson D, Stearns JA, Pischke SL, Greiten TL. Identifying disparities in colorectal cancer screening rates in Milwaukee-based academic and nonacademic clinics. J Patient Cent Res Rev. 2016;3:240-1.

Published quarterly by Midwest-based health system Advocate Aurora Health and indexed in PubMed Central, the Journal of Patient-Centered Research and Reviews (JPCRR) is an open access, peer-reviewed medical journal focused on disseminating scholarly works devoted to improving patient-centered care practices, health outcomes, and the patient experience. 
usage data. By potentially avoiding a diagnosis of HIT/HITT in these patients, the hospital would realize an annualized savings of over $\$ 86,000$.

Conclusion: Normal saline has demonstrated historical noninferiority to heparin for maintaining PICC patency when used as the capping solution with positive pressurized caps. Similar results were found during our pilot.

\section{Cost-Effectiveness of Genomic-Based Warfarin Therapy}

John Weissert, Kourosh Ravvaz

\section{Aurora Research Institute}

Background: With over 40 years of demonstrated clinical efficacy, warfarin remains the world's most used pharmaceutical to prevent ischemic stroke in patients with atrial fibrillation (AF). However, warfarin has many challenges. Thus, despite known effectiveness, warfarin is a leading cause to druginduced morbidity and mortality. Over 50 different warfarin therapy protocols, including a number of pharmacogenomicbased (PG) protocols, with as many as 14 independent variables, have been developed to improve safety and efficacy, thereby reducing ischemic strokes and intracranial hemorrhages (ICH). Purpose: To conduct a preliminary cost-effectiveness study to determine the price point at which using warfarin PG dosing to prevent ischemic stroke and ICH would provide a neutral cost difference for the AF patient population at Aurora Health Care. Methods: Using a 15-year retrospective electronic medical record, we generated a large enough simulated AF population using Bayesian Network modeling to conduct a series of simulated warfarin therapies. We used five different PG and non-PG warfarin therapy protocols. The protocols with various levels of personalization used different PG and non-PG dosing algorithms for initial, adjustment and maintenance warfarin dosing. The simulation platform was able to predict daily international normalized ratio values and the rate of ischemic stroke and ICH in each simulated patient over 90 days for each of the five warfarin therapy protocols. Using nationwide estimates derived through literature review, we estimated the total cost of administering warfarin using the five different protocols and subsequent acute and 5-year care costs (adjusted according to annual Medical Care Component of the Consumer Price Index).

Results: In 2000-2015, a total of 48,006 patients, or $\sim 3,000$ patients annually, initiated warfarin therapy with a primary diagnosis of AF at Aurora. We found that Aurora's current best practice warfarin therapy protocol had the highest predicted costs for ICH, resulting in $\$ 163,462.55$ for acute care costs (averaged over 1,000 patients) and $\$ 171,279.60$ for 5-year ongoing care related to ICH. The current Aurora protocol also had the highest associated costs for ischemic stroke at $\$ 51,333.45$ for acute care and $\$ 58,507.21$ for 5-year ongoing care. In contrast, PG-protocol 3, which incorporated patient's genotype into the warfarin dosing protocol, had the lowest predicted acute care and ongoing costs associated with ICH at $\$ 119,823.78$ for acute care and $\$ 125,462.75$ for ongoing care.
For 1,000 AF patients initiating warfarin therapy in Aurora, switching to a PG protocol would save $\$ 55,299.94$ in acute care costs and $\$ 59,198.50$ in 5-year ongoing care.

Conclusion: At a cost of $\$ 59.20$ per patient, warfarin PG dosing is cost neutral. With substantial decreases in genotyping cost in recent years, it is likely this price is currently achievable. Therefore, although there is only incremental clinical benefit from warfarin PG dosing, it is likely cost-effective.

\section{Identifying Disparities in Colorectal Cancer Screening Rates in Milwaukee-Based Academic and Nonacademic Clinics}

Jasmine Wiley, Jonathan J. Blaza, Will Lehmann, Deborah Simpson, Jeffrey A. Stearns, Shelby L. Pischke, Tracy L. Greiten

Department of Family Medicine, Aurora Health Care; Department of Family Medicine, Aurora UW Medical Group; Academic Affairs, Aurora UW Medical Group; Business Intelligence, Aurora Health Care; Operational Informatics, Aurora Health Care

Background: The Institute for Healthcare Improvement's Triple Aim focuses on improving the patient's experience of care, improving population health and reducing the per capita cost of health care. Health care systems and providers continuously seek to improve quality of care through understanding what percentage of their patients are achieving quality-of-care standards for various indicators, including immunizations, tobacco cessation, asthma and cancer screening. As health care moves toward reimbursing for value-based care, deepening our understanding of patient population characteristics within each of these conditions is vital to continuous quality improvement. Purpose: To determine if there are race/ethnicity/age/preferred language (REAL) disparities in care to patients 50 years old or older who are eligible for colorectal cancer (CRC) screening in family medicine residency clinics.

Methods: A retrospective analysis of all patients eligible for CRC screening at two Milwaukee-based family medicine residency teaching clinics (referred to as FM1 and FM2) and nonacademic clinics in greater Milwaukee (NAC-MKE) during a 12-month period (December 2014 - November 2015) was undertaken in collaboration with health care system quality improvement specialists. Percentage of patients achieving CRC screening metric was reported by REAL and gender. As the ultimate goal was to identify subpopulations to target for improvement, categories with $\mathrm{N}<25$ were omitted and criterion for disparity within a category was defined as $>10 \%$.

Results: The largest CRC screening disparity was associated with age, with gaps ranging from $13 \%$ to $15 \%$ between populations $>65$ years old versus 50-54 years old: NAC-MKE (79\% vs 66\%), FM1 (81\% vs 68\%), and FM2 (80\% vs 65\%). CRC screening disparities varied by black/African-American race per location, 54\% at NAC-MKE and 67\% at FM2 (N $\leq 25$ at FM1). Other race, ethnicity and gender were $<10 \%$.

Conclusion: Per the Centers for Disease Control and Prevention, the African-American/black race has the highest 
$\mathrm{CRC}$ death, making early $\mathrm{CRC}$ screening an imperative. While the Wisconsin Collaborative for Healthcare Quality ranks Aurora Health Care as eighth out of 20 systems in Wisconsin (77.6\% from 2014 Q3 to 2015 Q2), local data analysis identified age as the largest disparity gap. Analyzing local population REAL/gender data provides key insights to support initiatives to reduce health disparity gaps and further progress toward achieving the Triple Aim for health care.

\section{WISE-Family Medicine: A Statewide Faculty Development Collaborative}

Deborah Simpson, Kjersti Knox, Anne Getzin, John R. Brill, Melissa M. Stiles, Jeffrey A. Morzinski

Departments of Academic Affairs and Family Medicine, Aurora UW Medical Group; Department of Family Medicine and Community Health, University of Wisconsin School of Medicine and Public Health; Department of Family and Community Medicine, Medical College of Wisconsin

Background: In many states, family medicine residencies and medical schools compete clinically for patients, educationally for trainees and, more recently, for community preceptors (CPs). As Wisconsin's medical schools and health care systems have expanded their geographic footprints, our CPs now teach trainees from competing institutions. Yet residency and medical student accrediting bodies require faculty and preceptor development.

Purpose: To evaluate the impact of a statewide collaborative of family medicine educators on meeting faculty development needs of our CPs and collaborative members.

Methods: Faculty development leaders representing the three largest family medicine residency training sponsors in the state created the Wisconsin Institute of Scholars \& Educators in Family Medicine (WISE-FM). This statewide collaborative of family medicine educators is comprised of 3 to 4 representatives per sponsor — both junior and senior educators to further support their development as faculty - committed to developing common preceptor clinical teaching tools. Through online discussions and half-day WISE-FM meetings, WISEFM participants identified preceptor development needs and designed highly regarded clinical teacher infographics for these priority topics. These tools are available for use statewide, providing CPs with a consistent teaching approach. To determine infographic value, a brief ( $<5$ items) parallel form survey was distributed to and voluntarily completed by: 1) CPs who received the infographics, and 2) WISE-FM participants. Item results on a 5 -point Likert scale ( $5=$ strongly agree, $1=$ strongly disagree) were analyzed using descriptive statistics.

Results: Forty-two CP infographics recipients and the 11 WISEFM participants completed the evaluations. Results revealed that faculty development infographics were a time-efficient (CP: 4.1, WISE-FM: 4.2) and effective way (CP: 4.0, WISEFM: 4.2) to enrich skills as clinical teachers. Both groups intend to or have incorporated the infographics into their own teaching (CP: 4.2, WISE-FM: 4.2). WISE-FM respondents strongly agreed (4.6) that the overall "returns" from participating were worth their investments (time, effort).

Conclusion: The WISE-FM provides a statewide faculty development model that can be adopted by others to meet accreditation requirements for CP teaching skill development through shared authoring of $\mathrm{CP}$ development resources while concurrently advancing the development of WISE-FM participants.

\section{Evaluation of Preoperative Anemia and Transfusion Requirements in Adult Liver Transplant Recipients}

\section{Parissa M.N. Moghimi, Erika A. Aldag, Rachel Pedersen, Ajay Sahajpal, Jacob N. Clendenon, Vikraman Gunabushanam, Mehraboon S. Irani, David J. Kramer}

Departments of Pharmacy, Abdominal Transplant, Transfusion Services and Critical Care Medicine, Aurora Health Care

Background: Liver transplantation is often associated with massive blood loss due to surgical complexity and the hemostatic abnormalities of end-stage liver disease. Blood transfusions have been associated with increased risk of infection, multiorgan dysfunction, graft loss and mortality.

Purpose: To determine for liver transplantation whether correlation exists between preoperative anemia and transfusion requirements, length of stay or incidence of postoperative infection.

Methods: A retrospective review of liver transplantations from Jan. 1, 2012, to June 30, 2015, was conducted. Packed red blood cell (PRBC), fresh frozen plasma (FFP), platelet and cryoprecipitate units were collected preoperatively, intraoperatively and within the first 48 hours postoperatively. Cox proportional hazards model was used to model the outcome of infection. Linear regression was used to model the outcomes of postoperative length of stay and blood use.

Results: Of the 112 patients, mean age was 56 years, mean Model for End-Stage Liver Disease score was 27 and mean preoperative hemoglobin was $10.5 \mathrm{~g} / \mathrm{dL}$. Lower preoperative hemoglobin was significantly associated with increased preoperative $\mathrm{PRBC}$, platelet and cryoprecipitate use $(\mathrm{P}<0.04)$ as well as increased intraoperative PRBC, FFP, platelet and cryoprecipitate use $(\mathrm{P}<0.0001)$. Preoperative PRBC, FFP, and platelets as well as intraoperative PRBCs were associated with longer length of stay $(\mathrm{P}<0.045)$. Each $\mathrm{g} / \mathrm{dL}$ decrease in preoperative hemoglobin was associated with a $26 \%$ increased risk of infection in univariate models (hazard ratio $[\mathrm{HR}]$ : 1.26, $\mathrm{P}=0.01$ ). Longer length of stay and higher preoperative cryoprecipitate, intraoperative FFP and postoperative FFP also were associated with increased risk of infection. More units of preoperative cryoprecipitate (HR: $1.07, \mathrm{P}<0.01)$, fewer units of postoperative cryoprecipitate (HR: $0.19, \mathrm{P}<0.01$ ) and more units of postoperative FFP (HR: 1.75, $\mathrm{P}<0.01$ ) were associated with infection in multivariable stepwise selection.

Conclusion: Lower preoperative hemoglobin was associated with increased preoperative and intraoperative transfusion 